\title{
Place Matters: Community Level Effects of Women's Autonomy on Ethiopian Children's Immunization Status
}

\author{
Jane O. Ebot. \\ Department of Sociology and Population Research Center, University of Texas at Austin \\ 305 E. 23rd Street, Stop G2800, Austin, TX 78712-1699, USA \\ Phone number: (512) 378-3518; Fax number: 512-471-4886; Email: janeebot@utexas.edu
}

\begin{abstract}
Over $75 \%$ of Ethiopian children are not fully immunized against infectious diseases and illnesses. Studies have shown that women's autonomy, or decision-making abilities, is related to improvements in children's health. Yet the extent to which community-context measures of women's autonomy affect children's health has yet to receive adequate attention. This study uses data from the 20II Ethiopia Demographic and Health Survey to investigate the relationship between individual- and community-levels of women's autonomy and children's -- aged 12-30 months -- immunization status. The results of multilevel Poisson regression analysis show that community-level women's autonomy is associated with an increased number of children's immunizations above and beyond that of individual-level women's autonomy. Overall, these results indicate that empowering women within households is not only an important mechanism through which improvements in children's health can be made, but also serves as a way to improve the lives of other children within the community.
\end{abstract}

Keywords: Autonomy, Children, Community, Ethiopia, Immunizations

\section{Résumé}

Plus de $75 \%$ des enfants éthiopiens ne sont pas complètement vaccinés contre les maladies infectieuses et les maladies. Des études ont montré que l'autonomie des femmes, ou des capacités de prise de décision, est liée à l'amélioration de la santé des enfants. Pourtant, la mesure dans laquelle les mesures communautaires contexte de l'autonomie des femmes affecter la santé des enfants n'a pas encore reçu l'attention adéquate. Cette étude utilise les données de l' Ethiopie démographique $201 \mathrm{l}$ et Enquête sur la santé pour étudier la relation entre - personne et de son niveau de la communauté de l'autonomie des femmes et des enfants âgés de 12-30 mois - statut vaccinal. Les résultats de la régression de Poisson multiniveaux analyse montrent que l'autonomie de la communauté au niveau des femmes est associée à une augmentation du nombre de vaccinations des enfants au-delà de celle de l'autonomie des femmes au niveau individuel. Dans l'ensemble, ces résultats indiquent que l'autonomisation des femmes au sein des ménages n'est pas seulement un mécanisme important par lequel l'amélioration de la santé des enfants peuvent être faites, mais sert aussi comme un moyen d'améliorer la vie des autres enfants au sein de la communauté.

Mots clé: Autonomie, enfants, communautaires, l'Ethiopie, l'immunisation 


\section{Introduction}

The United Nations (UN) Millennium Development Goals (MDGs) are a set of key global initiatives which among others include halving extreme poverty and hunger to combating HIV/AIDS, malaria, and other infectious diseases. The MDGs are aimed at meeting the needs and improving the lives of the world's poorest and most vulnerable people. The fourth MDG (MDG 4) focuses on reducing child death rates in developing countries by two-thirds between 1990 and the 2015 target date (Black, Morris and Bryce 2003). Since the adoption of MDG 4, Sub-Saharan Africa (SSA) has reduced its underfive mortality rate by $39 \%$ (United Nations Statistics Division 2013). Despite this achievement, SSA's progress in reducing mortality has begun to slow down, leading many experts to predict that the continent will not meet MDG 4. In addition, SSA continues to carry the majority of the world's burden in under-five mortality and morbidity: estimates suggest that one in nine African children dies before the age of five and in $201 \mathrm{I}$, approximately 3.5 million African children died from preventable diseases and infections (United Nations [UN] 20I3).

In order to achieve country-specific MDG 4 targets, many SSA countries have implemented national immunization and vaccination campaigns as efficient and cost-effective methods to reduce child mortality and protect children against many lifethreatening infectious diseases. Though routine immunization schedules vary by country, the World Health Organization (WHO) recommends children be fully immunized against tuberculosis, diphtheria, pertussis (whooping cough), tetanus, polio, and measles by age 1 to prevent childhood infectious diseases. In 2012, approximately III million infants worldwide received the recommended 3 doses of diphtheria, pertussis, and tetanus (DPT3) and it is estimated that close to 2-3 million child deaths were averted by vaccinations. Yet in the same year, an estimated 16 million SSA children were not appropriately vaccinated (WHO 20I2).

Studies have identified maternal education and occupation (Basu and Stephenson 2005; Caldwell 1979), access to health services (Masudi 200I), and household wealth (Boyle et al. 2006) as key determinants of children's health. Recently, health organizations and researchers have increasingly focused attention on the importance of women's autonomy, or decision-making power, in improving children's health, especially in countries where women have low levels of socioeconomic status.
During the 1994 Cairo International Conference on Population and Development, policymakers from around the world called for greater focus on improving women's autonomy to address health needs in developing countries (Dancer and Rammohan 2009). The UN MDG 3 promotes gender equality and women's autonomy as important means of improving women's and children's health outcomes (United Nations Development Group [UNDG], 20I2).

Greater women's autonomy has been linked to reductions in infant mortality (Castle 1995; Doan and Bisharat 1990), better child nutritional outcomes (Brunson, Shell-Duncan and Steele 2009; Dancer and Rammohan 2009), and increased use of health care services (Woldemicael 2010; Woldemicael and Tenkorang 2010) in both South Asia and SSA. However, little research has focused on the relationship between women's autonomy and children's immunization status (Singh, Haney and Olorunsaiye 20I2), despite its recognized importance in improving children's health and odds of survival. In addition, children's immunization status is a key indicator of governments' commitments to health investments in children's long-term health.

Beyond individual women's autonomy, few studies have examined whether the autonomy of other female community members may influence children's health. Many studies have shown that measures of community context including education, wealth, literacy, and health infrastructure influence children's mortality (Kravdal 2004), children's nutrition (Fotso and Kuate-Defo 2006; Linnemayr, Alderman and $\mathrm{Ka} \mathrm{2008}$ ), and women's health knowledge (Andrzejewski, Reed and White 2009), and children's immunization status. Yet, there are few studies that examine how children's immunization status may be influenced by women's autonomy at the community level (Antai 2009; Babalola 2009). The decision making capabilities of women in a community might have an effect on children's immunization status, above and beyond the effect of individual women's autonomy. Indeed community-level women's autonomy may matter for two reasons. Firstly, direct communication and contact with more autonomous female community members provides less autonomous women with greater knowledge and behaviors that are associated with better health outcomes for both women and children (Koenig et al. 2003; Moursund and Kravdal 2003). Second, communities with higher averages of women's autonomy might be more economically 
advantaged because more women are working outside the home. More economically advantaged communities might also make greater investments in the health sector, allowing less autonomous women greater access to health services for their children (Kravdal 2004).

The aims of this study are to: a) analyze the association between women's autonomy at the individual-level and Ethiopian children's vaccinations; and b) determine to what extent community context, especially average levels of women's autonomy, is related to Ethiopian children's vaccinations.

Ethiopia is the setting for this analysis because it is characterized by both low levels of full immunization coverage and women's autonomy. Ethiopia, SSA second poorest country, is also one of the few African countries that is expected to achieve its country-specific MDG 4 of reducing under-five mortality from 190 to 63 deaths per 1000 live births by 2015 (United Nations Development Programme [UNDP] 2012). Between 1990 and 2010, under-five mortality rates declined from 167 to 88 deaths per I,000 children, an average annual decline of $6.3 \%$. Among the many government-sponsored health sector initiatives, the increase of immunization coverage has been a key method toward successfully meeting MDG 4. As of 2010, progress in immunization coverage against diphtheria, pertussis, tetanus, and measles increased, though more than $75 \%$ of Ethiopian children were still not fully vaccinated (Central Statistical Agency [CSA] 20I2).

Over $70 \%$ of Ethiopian women do not receive a formal education (CSA 20I2). By age 16, most Ethiopian women leave their families and communities for their new husband's village or home (Hogan, Berhanu and Hailemariam 1999), which increases their risk of intimate partner violence and potentially decreases autonomy (Gómez and Speizer 2010). Ethiopian women have high adolescent birth and total fertility rates: the 2010 adolescent birth rate was 109 births per 1,000 women, the 15th highest in the world and the current total fertility rate is 5.4 births per woman (Central Intelligence Agency 2013). Early childbearing and number of children ever born are negatively related to both autonomy and children's health and care (Prakash et al. 20II). Thus, investigating the extent to which Ethiopian women's autonomy at both the individual and community levels is related to children's immunization -- net of women's educational attainment -- is important for both theoretical and policy reasons.

\section{Theoretical Framework}

This study's theoretical framework is a modification of Mosley and Chen's (1984) approach to understanding the social and biological proximate determinants of childhood survival in developing countries. Mosley and Chen (1984) theorized that socioeconomic-status determinants, grouped into three broad categories, individual-level variables (individual productivity, traditions/norms/attitudes), household-level variables (income/wealth) and community-level variables (ecological setting, political economy, health system), influence children's nutrition, mortality, and morbidity outcomes. When these pathways negatively affect children, children's health suffers. Borrowing from Barbara Entwisle's (2007) "Putting People into Place", this study emphasizes the importance of "place context", in this case a geographically designated community, as a key pathway that affects children's health.

\section{Literature Review}

Women's autonomy refers to the capacity of women to manipulate and have control over their personal environments in order to make decisions about their livelihood, regardless of other men and women's opinions (Hindin 2006; Mistry, Galal and Lu 2009). Women's autonomy does not symbolize their overall status within society: instead, it is a reflection of their personal and household capacities in relation to their husbands, fathers, or in-laws (Mistry, Galal and Lu 2009). Dimensions of women's autonomy are categorized into three groups: physical autonomy, decision-making autonomy, and economic autonomy (Becker, Fonseca-Becker and Schenck-Yglesias 2006; Bloom, Wypij and Das Gupta 200 I; Jejeebhoy 1995). Physical autonomy is related to women's freedom of movement outside the home. Decision-making autonomy is related to women being able to have conversations with household members, where they are heard and have a say in final decisions and outcomes. Economic autonomy is related to women's access to economic resources. Therefore, improvements in women's autonomy increases their ability to control (solely or equally) most if not all aspects of their lives, including their educational, occupational, and health-related decisions (Dancer and Rammohan 2009).

Women's autonomy is not only related to their livelihoods, but also to their children's well-being. As children's primary care-givers, women are directly involved in health decisions. More autonomous women are more likely to be able to improve and 
maintain children's health in comparison to less autonomous women, who would have to defer all health care and household decisions to their husbands or older/other household heads (Doan and Bisharat 1990; Ngom et al. 2003). For example, before children are born, more autonomous women would have access to safe delivery services and prenatal care, which would influence the knowledge and access they have in relation to vaccine campaigns and information. After children are born, women with more freedom to move outside the home would be more likely to travel with their children to local health facilities for necessary health services like vaccinations. Financial freedom would allow women to use either their own income or a portion of the total household income to pay for all WHO recommended vaccinations.

Though it is important to understand how each of these dimensions is related to improvements in children's health, it should be noted that these dimensions of women's autonomy are rarely considered independent of each other. This analysis combines the effects of physical, financial, and decision-making autonomy on children's immunizations in order to provide an overall understanding of women's total autonomy.

Studies have provided evidence showing a positive relationship between women's autonomy and children's health status. Brunson, Shell-Duncan, and Steele (2009) found that among the Rendille of northern Kenya, higher levels of women's household autonomy were associated with increases in children's nutritional status. In Amman, Jordan, women's household bargaining power had a positive effect on children's well-being and nutritional status (Doan and Bisharat 1990). Woldemicael and Tenkorang (2010) analyzed the relationship between women's autonomy and health seeking behavior in Ethiopia and found that overall, more autonomous Ethiopian women were more likely to access health care compared to Ethiopian women with little household autonomy. Woldemicael (2010) further used Demographic and Health Survey data from Ethiopia and Eritrea to show that, net of socioeconomic-status, physical autonomy increased the use of antenatal care in both countries, though sole decision-making about household purchases increased antenatal care only in Eritrea. Singh et al. (20I2) also found that Nigerian women's decisionmaking abilities and negative attitudes towards wifebeating increased children's odds of being fully immunized, net of mother's education, work status, and household wealth.
As previously stated, community-context variables have also been identified as important predictors of children's health outcomes, net of individual-level characteristics. Yet the relationship between community-level autonomy and children's immunization status has not been examined. First, women communicate with other women in the context of communities. Women are members of small sub-groups, which when combined, span an entire community. Through indirect and direct contact, less autonomous women might learn the knowledge and attitudes of more autonomous women, including decision-making abilities related to children's health. Less autonomous women might not gain control of all aspects of their lives, but might use this knowledge to increase their personal decision making abilities about children's health.

Secondly, communities with high average levels of autonomy have been characterized as having more liberal ideas concerning women having control of most aspects of their lives, including their education and occupation (Bloom, Wypij and Das Gupta 200I). Increases in women's educational attainment and the number of women working outside the household might also increase women's overall status within a community. Such economic and social power might also be related to women's greater investments in the health sector. Therefore, residing in a community with high levels of women's autonomy potentially may allow less autonomous women more societal freedom to make decisions about their children's health compared to women living in communities with low average autonomy.

This research adds to past work on women's autonomy and children's health in two key ways. First, it builds on the foundational research that shows a positive relationship between women's autonomy and children's health (Ghuman 2003; Hindin 2005; Singh, Haney and Olorunsaiye 20I2) by using actual measurements of women's household decision-making abilities instead of proxy measurements such as women's education, labor force participation, or age at first marriage. Second, previous studies on children's immunization status have solely focused on individual level women's autonomy. This study includes a measure of community-level women's autonomy as well, to better understand the relationship between women's autonomy and children's immunization status.

\section{Data and Methods}

Data came from the 20II Ethiopia Demographic and Health Survey (EDHS), which contains 
information on fertility and family planning behavior, child mortality, children's nutritional status, maternal and child health services, and knowledge of HIV/AIDS. The 20II EDHS uses a two-stage sampling frame. In the first stage, data from the 2007 national census were used to divide primary sampling units into 187 urban and 437 rural clusters. In the second stage, a sample of households in all 624 clusters was interviewed. Each cluster consisted of approximately 27 households. Overall, the 2011 EDHS included complete interviews from 16,702 households, 16,515 women aged 15-49 years, and 14, I 10 men aged I5-59 years. This study focuses on the 2,94I children aged 12-30 months of currently married women aged 15-49 years in the survey. The child age limits were based on WHO recommendations that children be fully immunized by 12 months of age, with a 30-month upper-limit to cover the cases where children were somewhat late in getting all the vaccines.

This study's dependent variable is children's number of immunizations, an important health indicator because immunizations are one of the earliest ways parents can prevent common childhood diseases/infections. The 20II EDHS collected information on children's immunizations from vaccination cards and mothers' verbal responses. The vaccination cards represent routine vaccines whereas maternal recall encompasses both routine vaccines and those done through immunization campaigns. A fully immunized child has received I dose against tuberculosis (BCG); 3 doses each against diphtheria, pertussis, and tetanus (DPT3) and polio; and I dose against measles. Children's number of immunizations was coded as an interval variable ranging from $0-8$ vaccines.

\section{Ethical Considerations}

This study is based on an analysis of survey data with all identifying information removed. The 201 I EDHS was approved by the Ethiopia Health and Nutrition Research Institute (EHNRI) Review Board, the National Research Ethics Review Committee (NRERC) at the Ministry of Science and Technology, the Institutional Review Board of ICF, and the CDC. All study participants gave informed consent before participation and all information was collected confidentially.

\section{Individual Level Variables}

The primary individual-level independent variable, women's autonomy, was gauged through $201 \mathrm{I}$ EDHS questions asking women about their decision-making abilities related to the purchase of household goods, visits to family/relatives, spending money, and obtaining health care. Each of these measures served as dimensions of the overall autonomy index, which ranged from 0-4. This score corresponds to the number of decisions in which women reported participating alone or jointly; a high score on the autonomy index indicates a higher level of household autonomy. Two dichotomous measures of women's access to healthcare during their pregnancies were also included: women who delivered their last child in a hospital/clinic/health care facility versus women who delivered at home and women who received some form of prenatal care for their latest pregnancy versus women who received no prenatal care. The prenatal care measure captures women's access to health practitioners and health information; including information on the importance of immunizing children and where to get this service done. Delivery location is an indicator of women's quality of care and access to preventative measures, like immunizations, against common childhood diseases and illnesses

To best estimate the relationship between women's autonomy and immunization, I control for women's socioeconomic-status. Women's educational attainment was measured in three categories due to small cell counts at the higher levels of education: no education, incomplete primary school education, and complete primary school and higher. Women's occupation was coded into four categories: no occupation, manual, agriculture, and professional sector. Women's household wealth status was measured with quintiles constructed by the 20II EDHS: lowest, second, middle, fourth, highest.

Additional control variables included urban/rural residential location, polyginous marriage, religion, women's age in years, age at first marriage, child's age, child's sex, and number of children under 5 years of age living in the household. Polyginous marriage was measured as a dichotomous variable: women who were an only wife versus women who were not an only wife. Religion was measured in four categories: Orthodox/Catholic, Protestant, Muslim, and Traditional/Other. Mother's age, age at first marriage, child's age, and number of children under 5 years of age living in the household were measured as continuous variables.

\section{Community-Level Variables}

The analysis included five community-level variables. While the 20II EDHS does not specifically include community-level measures, the average levels of variables in each geographic cluster 
provided an effective proxy of community-level measures "surrounding" children and women. As previously stated, the 20I I EDHS has a total of 624 clusters; thus, the community-level variables refer to the aggregated measures in each of these clusters. In the Somali region 28 clusters were not included in the data because of drought and security reasons. An additional 16 clusters were not included in this analysis because there were no children between the 12-30 months of age. Overall, then, this analysis included women/children living in 580 clusters.

Community-level women's autonomy measures the average number of household decisions that all women aged 15-49 in each cluster made alone or jointly. This variable ranged from $1-4$, with a high score indicating that a community has a high average level of women's autonomy.

Second, community-level women's education was calculated by averaging the years of schooling for all women aged 15-49 with non-missing responses of education in years in each cluster. After calculating the distributions of mean years of education for each cluster, I divided communities into 3 categories of average education: low average community education (less than 4 years), middle average community education (more than 4 but less than 8 years), and high average community education (8 or more years).

Third, community-level prenatal care was defined as the mean prenatal score for all mothers aged 15 49 in each cluster. Women who received prenatal care for their last pregnancy were given a value of $I$ and women who did not receive prenatal care for their last pregnancy were given a value of 0 . Then, each value for all women in each cluster was used to calculate an average cluster prenatal access score, which ranged from 0-0.77. Next, scores were collapsed into two categories, low versus high access to prenatal care, using a cut-off at 0.50 (Antai 2009).

Community-level delivery care was defined as the mean delivery score for all mothers aged 15-49 in each cluster. Women who delivered their last child in a hospital/clinic/health care facility were given a value of $\mathrm{I}$ and women who did not deliver their last child in a hospital/clinic/health care facility were given a value of 0 . Then, each value for all women in each cluster was used to calculate an average cluster delivery care score, which ranged from 0-0.52. Communities with an average delivery score of 0 were categorized as having low hospital delivery access. Communities with average delivery scores between 0.03 and 0.09 were categorized as having middle hospital delivery access. Communities with average delivery scores higher than 0.10 were categorized as having high hospital delivery access (Antai 2009).

Finally, I included a categorical variable measuring geographic region: Tigray, Affar, Amhara, Oromiya, Somali, Benishangul Gumuz, Southern Nations Nationalities Peoples (SNNP), Gambela, Harari, Dire-Dawa, and Addis Ababa.

\section{Methods}

Multilevel modeling methods are used because individuals are clustered within communities. I use multivariate multilevel Poisson regression equations that have accounted for over dispersion, to predict children's number of immunizations using individuallevel (level-I) and community-level (level-2) covariates. Model I estimates a two-level unconditional means or empty model, which is used to calculate the intra-class correlation (ICC). This assesses whether there is significant variation between communities in the number of vaccinations. The ICC also informs researchers whether or not multilevel modeling is an appropriate method of estimation (Raudenbush and Bryk 2002). Previous research has shown that ICC values between 0.05 and 0.20 are common in crosssectional multilevel modeling applications in social research studies (Peugh 20I0). Model 2 includes the effects of individual-level women's autonomy and health care access. Model 3 further includes women's socioeconomic status, to assess whether individual-level autonomy withstands controls for maternal socioeconomic status. Model 4 specifically analyzed the relationship between community-level variables and children's number of immunizations. Finally, Model 5 is the full model that includes all the individual- and community-level variables. Most importantly, this model assesses whether community-level women's autonomy is associated with children's immunization, net of both individuallevel and community-level covariates.

All the models were estimated using HLM7 software, which is commonly used to analyze data from clustered samples, which in this case is children nested within communities (Raudenbush et al. 2004). All individual-level variables were centered around the grand mean, which means that individual characteristics were converted into deviations from the overall sample mean. This process also reduces multicollinearity in the models. All analyses were weighted to take into account the 201I EDHS cluster sampling design. 


\section{Results}

Table I displays the weighted descriptive statistics for all variables. Overall mean number of immunizations for Ethiopian children was approximately 4.7. About $15 \%$ of all children had 0 immunizations while $24.1 \%$ of all children were fully immunized. The individual-level autonomy index mean of 3.1 means that on average, most women made about 3 out of 4 decisions alone or jointly. Approximately $10 \%$ of women delivered their last child in a hospital and about $36 \%$ of women received some form of prenatal care. About $69 \%$ of mothers did not receive a formal education, $47 \%$ of mothers were not in the labor force, and households were evenly spread across the wealth categories. Across all communities the average autonomy score was 3.7. Most communities (71\%) had low average levels of women's education. The majority of communities had low access to prenatal care $(97 \%)$ and low access to hospital delivery (43\%). 


\begin{tabular}{|c|c|c|}
\hline & Percent \% & $\mathrm{Cl}$ \\
\hline Number of immunizations & 4.7 (mean) & $(4.4-5.0)$ \\
\hline 0 & 14.9 & $(\mid 1.9-18.5)$ \\
\hline I & 3.6 & $(2.6-5.1)$ \\
\hline 2 & 7.1 & $(5.6-8.8)$ \\
\hline 3 & 9.7 & $(7.9-12.0)$ \\
\hline 4 & 8.6 & $(7.1-10.4)$ \\
\hline 5 & 9.1 & $(7.6-10.8)$ \\
\hline 6 & 10.2 & $(8.7-12.0)$ \\
\hline 7 & 12.7 & $(10.9-14.7)$ \\
\hline 8 & 24.1 & $(21.3-27.1)$ \\
\hline \multicolumn{3}{|l|}{ INDIVIDUAL-LEVEL VARIABLES } \\
\hline Autonomy Index (0-4) & 3.1 (mean) & $(3.0-3.2)$ \\
\hline Delivered in hospital & 10.2 & $(8.6-12.2)$ \\
\hline Prenatal care & 36 & $(33.0-39.1)$ \\
\hline \multicolumn{3}{|l|}{ Individual level of Educational Attainment } \\
\hline No education (reference category) & 68.8 & $(65.5-71.9)$ \\
\hline Incomplete primary school & 24.9 & $(22.1-27.9)$ \\
\hline Complete primary school and higher & 6.3 & $(5.1-7.9)$ \\
\hline \multicolumn{3}{|l|}{ Occupation } \\
\hline No occupation (reference category) & 47.2 & $(43.7-50.7)$ \\
\hline Manual & 7.2 & $(5.6-9.2)$ \\
\hline Agriculture & 26.9 & $(23.8-30.3)$ \\
\hline Professional & 18.7 & $(|6.0-2| .8)$ \\
\hline \multicolumn{3}{|l|}{ Household Wealth } \\
\hline Lowest & 23.0 & $(19.8-26.5)$ \\
\hline Second & 22.1 & $(19.7-24.7)$ \\
\hline Middle & 20.9 & $(18.6-23.4)$ \\
\hline Fourth & 19.3 & $(16.5-22.5)$ \\
\hline Highest (reference category) & 14.7 & $(12.7-16.8)$ \\
\hline \multicolumn{3}{|l|}{ COMMUNITY-LEVEL VARIABLES } \\
\hline Community-level autonomy & 3.7 (mean) & $(3.7-3.8)$ \\
\hline \multicolumn{3}{|l|}{ Community-level education } \\
\hline Low average education (reference category) & 71.0 & \\
\hline Middle education & 16.0 & \\
\hline High average education & 13.0 & \\
\hline \multicolumn{3}{|l|}{ Community-level access to prenatal } \\
\hline Low access to prenatal (reference category) & 97.0 & \\
\hline High access to prenatal & 3.0 & \\
\hline Community-level hospital delivery & & $(0.1-0.8)$ \\
\hline Low access to hospital delivery( reference category) & 43.0 & \\
\hline Middle access to hospital delivery & 27.0 & \\
\hline High access to hospital delivery & 30.0 & \\
\hline
\end{tabular}

The multilevel multivariate Poisson regressions with fixed effects predicting number of immunizations are displayed in Table 2. To make the interpretations more straightforward, I describe the exponentiated coefficients. Results from the empty model (Model I) show that the grand mean of immunizations was significantly different between children $\left(\mathrm{Y}_{00}=\mathrm{I} .54, \mathrm{p}<.00 \mathrm{I}\right)$, the ICC was 0.13 , and there was significant variance in number of immunizations across communities $\left(\mathrm{T}_{00}=0.18\right.$, $\mathrm{p}<.00 \mathrm{I})$. The results in Model 2 show that a one unit increase in women's individual-level autonomy is associated with a $5 \%$ unit increase in children's number of immunizations. Number of 
immunizations for children whose mothers received prenatal care was $33 \%$ units higher than that of children whose mothers did not receive prenatal care. The inclusion of individual-level women's socioeconomic status variables in Model 3, especially household wealth and women's education, had significant effects on children's number of immunizations, but did not reduce the positive effect of women's own autonomy. Children whose mothers had incomplete primary school or completed primary school, had 1.09 and 1.10 times the number of immunizations relative to children whose mothers had no formal education, respectively. Children who resided in the lowest, second, or middle wealth households received fewer immunizations than children who resided in the highest wealth households.
Model 4 is a community-level specific analysis. At a glance, the results show that all the measures of community context matter for children's number of immunizations. One unit increases in a community's level of women's autonomy is associated with a $31 \%$ increase in children's number of immunizations. Relative to children residing in low average education communities, children in high average education communities had 1.32 times higher number of immunizations. Children residing in communities with a high proportion of women who received prenatal had $32 \%$ more immunizations than children who lived in communities with a low proportion of women who received prenatal care, though the association is marginal. Finally, communities with a high proportion of women who delivered in a hospital increased children's immunizations by $22 \%$ relative to communities with low hospital delivery. 


\begin{tabular}{|c|c|c|c|c|c|}
\hline $\begin{array}{l}\text { Table 2: Multilevel } \\
\text { Immunizations }\end{array}$ & Poisson & Regressions Predicting & Ethiopian & Children's & Number of \\
\hline & $\mathrm{I}$ & 2 & 3 & 4 & 5 \\
\hline \multirow[t]{2}{*}{ Intercept } & $1.54 * * *$ & $1.50 * * *$ & $1.47 * * *$ & $1.55^{* * * *}$ & $1.50 * * *$ \\
\hline & {$[4.66]$} & {$[4.48]$} & {$[4.36]$} & {$[4.73]$} & {$[4.5 \mathrm{I}]$} \\
\hline \multicolumn{6}{|l|}{ INDIVIDUAL LEVEL } \\
\hline \multirow[t]{2}{*}{ Autonomy Index } & & $0.05 * *$ & $0.05 * *$ & & $0.04 * *$ \\
\hline & & {$[1.05]$} & {$[1.05]$} & & {$[1.04]$} \\
\hline \multirow[t]{2}{*}{ Delivered at hospital } & & 0.05 & 0.01 & & -0.02 \\
\hline & & {$[1.05]$} & {$[1.02]$} & & {$[0.98]$} \\
\hline \multirow[t]{2}{*}{ Prenatal care } & & $0.29 * * *$ & $0.26 * * *$ & & $0.25 * * *$ \\
\hline & & {$[1.33]$} & {$[1.30]$} & & {$[1.29]$} \\
\hline \multicolumn{6}{|l|}{ Education } \\
\hline \multicolumn{6}{|l|}{ No education (reference category) } \\
\hline \multirow[t]{2}{*}{ Incomplete primary school } & & & $0.08 *$ & & $0.08 *$ \\
\hline & & & {$[1.09]$} & & {$[1.08]$} \\
\hline \multicolumn{2}{|l|}{$\begin{array}{l}\text { Complete primary school and } \\
\text { higher }\end{array}$} & & $\begin{array}{l}0.09+ \\
{[1.10]}\end{array}$ & & $\begin{array}{l}0.08+ \\
{[1.09]}\end{array}$ \\
\hline \multicolumn{6}{|l|}{ Occupation } \\
\hline \multicolumn{6}{|l|}{$\begin{array}{l}\text { No occupation } \quad \text { (Reference } \\
\text { category) }\end{array}$} \\
\hline \multirow[t]{2}{*}{ Manual occupation } & & & -0.10 & & -0.10 \\
\hline & & & {$[0.91]$} & & {$[0.91]$} \\
\hline \multirow[t]{2}{*}{ Agriculture occupation } & & & 0.05 & & 0.04 \\
\hline & & & {$[1.06]$} & & {$[1.04]$} \\
\hline \multirow[t]{2}{*}{ Professional occupation } & & & 0.06 & & 0.04 \\
\hline & & & {$[1.06]$} & & {$[1.04]$} \\
\hline \multicolumn{6}{|l|}{ Wealth Index } \\
\hline \multirow[t]{2}{*}{ Lowest } & & & $-0.20 * *$ & & $-0.16+$ \\
\hline & & & {$[0.82]$} & & {$[0.86]$} \\
\hline \multirow[t]{2}{*}{ Second } & & & $-0.14+$ & & -0.11 \\
\hline & & & {$[0.87]$} & & {$[0.90]$} \\
\hline \multirow[t]{2}{*}{ Middle } & & & $-0.18 *$ & & $-0.14+$ \\
\hline & & & {$[0.83]$} & & {$[0.87]$} \\
\hline \multirow[t]{2}{*}{ Fourth } & & & -0.12 & & -0.09 \\
\hline & & & {$[0.88]$} & & {$[0.92]$} \\
\hline \multicolumn{6}{|l|}{ Highest (Reference category) } \\
\hline \multicolumn{6}{|l|}{ COMMUNITY LEVEL } \\
\hline Community level autonomy & & & & $0.27 * *$ & $0.23 *$ \\
\hline & & & & {$[|.3|]$} & {$[1.25]$} \\
\hline Community level education & & & & & \\
\hline Low(Reference category) & & & & & \\
\hline Medium & & & & 0.08 & 0.00 \\
\hline & & & & [1.08] & {$[1.00]$} \\
\hline High & & & & $0.28 * *$ & $0.17+$ \\
\hline & & & & {$[1.32]$} & {$[1.18]$} \\
\hline $\begin{array}{l}\text { Community level access to } \\
\text { prenatal }\end{array}$ & & & & & \\
\hline Low (Reference category) & & & & & \\
\hline High & & & & $0.13+$ & 0.04 \\
\hline & & & & {$[1.14]$} & {$[1.04]$} \\
\hline $\begin{array}{l}\text { Community level hospital } \\
\text { delivery }\end{array}$ & & & & & \\
\hline Low (Reference category) & & & & & \\
\hline Medium & & & & $\begin{array}{l}0.09+ \\
{[1.09]}\end{array}$ & $\begin{array}{l}0.06 \\
{[1.07]}\end{array}$ \\
\hline High & & & & $0.20 *$ & 0.15 \\
\hline
\end{tabular}


VARIANCE COMPONENTS

\section{(Random Effects)}

Intercept

Residual

\section{$0.18 * * *$}

1.24

$X^{2}$

Explained variation (PVC)\%

ICC

Model log likelihood

\subsection{9}

Reference

0.13

$-4.89$

$0.12 * * *$
1.20
1837.01
33.33
0.09
-6.71

$0.11 * * *$

1.19

1773.03

$0.09 * * *$

$0.08 * * *$

1.24

1572.81

1.19

1498.38

12.5

0.06

0.08

18.2

0.07

$-6.62$

Source: 201 I Ethiopia Demographic Health Surveys

' Coefficient above brackets

${ }^{2}$ Exponentiated coefficient in brackets

$3 * * * \mathrm{p}<0.0001,{ }^{* *} \mathrm{p}<0.01,{ }^{*} \mathrm{p}<0.05,+\mathrm{p}<0.10$

${ }^{4}$ Models 2-4 controlled for urban residence, polyginous marriage, religion, women's age in years, women's age in years squared, age at first marriage, child's age in months, child's age in months squared, child's sex, and number of children under 5 years of age in household

Model 5 presents the key results in this paper by assessing the effects of community-level measurements, including autonomy, education, hospital delivery, and prenatal care access. The results show that community-level measures positively influence children's number of immunizations, net of individual-level covariates. Specifically, the results provide evidence that the autonomy of other female community member, matters for children's health. Each one unit increase in community-level average women's autonomy is associated with a $25 \%$ increase in children's number of immunizations. In addition, children who live in high average education communities receive 1.18 times the number of immunizations compared to children who live in low average education communities.

\section{Discussion}

This study examined the relationship between community-level women's autonomy and Ethiopian children's immunization status. Several studies have showed how higher women's autonomy is positively related to children's health (Boehmer and Williamson 1996; Doan and Bisharat 1990; Woldemicael and Tenkorang 2010), yet few have looked at how community context matters in relation to children's immunization status. This study showed that community-level women's autonomy is positively associated with children's number of immunizations, net of individual and community level socioeconomic-status and health access measures. The community-level measure might indicate that even if Ethiopian women have low autonomy, living in a community with high women's decision-making power can result in increased use of preventative health services and eventually, improvements in children's health. In addition, community-level education might also represent the overall community socioeconomic status. That is high autonomy communities might also be characterized as having more women working outside the home in higher paying positions. Therefore women in these communities might have more personal and shared resources that can be used to improve their family members' livelihoods, especially children. Overall these results show that children are at greater risk of contracting childhood diseases and infections in settings where women have very little autonomy. Though this result does not provide enough detail concerning the underlying mechanisms, it might be that it is in line with my hypothesis, given that previous studies have shown that community context matters for children's health in SSA (Kravdal 2004; Moursund and Kravdal 2003; Pongou, Ezzati and Salomon 2006).

This study also showed that living in a community with low proportion of women who deliver their child in a hospital or who received prenatal care, was not associated with children's number of immunizations, though interpretations of these results should be made lightly. Descriptive analyses showed that around $30 \%$ and $3 \%$ of communities had a high proportion of women who delivered in a hospital or had prenatal care for their last pregnancy, respectively. These measures lack of statistical significance might be less rooted in their inherent disassociation with children's immunization status but in the overall low access of these health services. Therefore closer attention should be focused on how community-based initiatives can target women's specific health service needs (hospital delivery and prenatal care) as the most important preventive measure against poor child health outcomes.

It should further be noted that children also received more immunizations in high average 
education communities, though this effect was marginal. Education has typically been used as a proxy measure of women's autonomy yet these results show that education is not a complete substitute for autonomy. It seems that Ethiopian women's autonomy is not only created through access to secondary schooling, but also through greater freedom to make decisions concerning their livelihoods.

A second key finding was the positive impact of individual-level women's autonomy and prenatal care on children's number of immunizations. Even the inclusion of women's individual level educational attainment, household wealth, and occupation, did not dampen the robust and significant relationship between women's overall participation in decisions related to their movement, household purchases, earnings, use of prenatal care, and their children's immunization status. It should be noted though, that women's household decision-making abilities were not as important to children's immunization as women's use of prenatal care. Women who make frequent visits to a trained health practitioner are most likely receiving proper health care and counseling before and during the birth of their child, which not only affects children's survival chances, but also women's knowledge and access to preventative measures (Choi and Lee 2006; Mistry, Galal and Lu 2009).

This study is not without limitations. First, the cross-sectional nature of the EDHS means that causal relationships between multilevel measures of women's autonomy and children's immunization status cannot be established with certainty. Second, this study relied on individual-level measures to aggregate to the community. The availability of specific measures at the community-level would produce a better estimate of the effect of the environment on children's immunization and reduce the problem of ecological fallacy. Third this study did not shed enough light on the specific nature of how increased autonomy at the community-level affects children's immunization status. Community-level women's autonomy was measured as a composite measure, which does not allow for a clearer understanding of how, for example, financial autonomy is related to children's health. A more detailed interpretation would be important for policy relevant purposes. Finally, the communitylevel women's autonomy measure used here only captures women's status within households and does not measure women's overall societal status, which might be the actual mechanism through which children's health is affected. In addition, this study does not include other individual and community level determinants of children's number of immunizations, which can increase the potential of biases in the results as well as reduce validity.

\section{Conclusion}

Overall, this study adds to an accumulating body of evidence that shows that place does matter for health outcomes; specifically, that community context and women's autonomy both are critical in shaping children's health. This study reaffirms the importance for health initiatives and programs to consider gender-related initiatives that target women's autonomy, not only with the expectation that it directly affects women's power and their children's well-being, but further in the hope that it works beyond the walls of women's homes to improve the health of other children within their communities. Specifically, the results show that the Ethiopian Ministry of Health and international organizations must incorporate several key factors in their development of programs targeting at increasing use of immunization services including: increasing women's rights within the household and society through education programs and a shift in gender norms; providing timely and effective access to prenatal care and safe delivery care services; and incorporating community members, especially women, in the planning and implementation of health initiatives.

\section{Author Guarantee Form:}

This author contributed sufficiently to this work submitted and the content of this manuscript has never been previously published. 


\section{References}

Andrzejewski, Catherine S., Holly E. Reed, and Michael J. White. 2009. "Does where you live influence what you know? Community effects on health knowledge in Ghana." Health \& Place I5(I):228-38.

Antai, Diddy. 2009. "Inequitable childhood immunization uptake in Nigeria: a multilevel analysis of individual and contextual determinants." BMC Infectious Diseases 9(I): I8I.

Babalola, S. 2009. "Determinants of the Uptake of the Full Dose of Diphtheria-Pertussis-Tetanus Vaccines (DPT3) in Northern Nigeria: A Multilevel Analysis." Maternal and Child Health Journal I3(4):550-58.

Basu, Alaka Malwade, and Rob Stephenson. 2005.

"Low levels of maternal education and the proximate determinants of childhood mortality: a little learning is not a dangerous thing." Social Science \& Medicine 60(9):20 I I-23.

Becker, Stan, Fannie Fonseca-Becker, and Catherine Schenck-Yglesias. 2006. "Husbands' and wives' reports of women's decision-making power in Western Guatemala and their effects on preventive health behaviors." Social Science \& Medicine 62(9):23।3-26.

Black, R. E., S. S. Morris, and J. Bryce. 2003. "Where and why are 10 million children dying every year?" Lancet 36I(9376):2226-34.

Bloom, S. S., D. Wypij, and M. Das Gupta. 200I. "Dimensions of women's autonomy and the influence on maternal health care utilization in a North Indian city." Demography 38(I):67-78.

Boehmer, Ulrike, and John B. Williamson. 1996. "The Impact of Women's Status on Infant Mortality Rate: A Cross-National Analysis." Social Indicators Research 37(3):333-60.

Boyle, Michael H., Yvonne Racine, Katholiki Georgiades, Dana Snelling, Sungjin Hong, Walter Omariba, Patricia Hurley, and Purnima RaoMelacini. 2006. "The influence of economic development level, household wealth and maternal education on child health in the developing world." Social Science \& Medicine 63(8):2242-54.

Brunson, Emily K., Bettina Shell-Duncan, and Matthew Steele. 2009. "Women's autonomy and its relationship to children's nutrition among the Rendille of northern Kenya." American Journal of Human Biology $2 \mathrm{I}(\mathrm{I}): 55-64$.
Caldwell, J. C. 1979. "Education as a Factor in Mortality Decline An Examination of Nigerian Data." Population Studies 33(3):395-4I 3.

Castle, Sarah E. 1995. "Child fostering and children's nutritional outcomes in rural Mali: The role of female status in directing child transfers." Social Science \&amp; Medicine 40(5):679-93.

Central Intelligence Agency. 2013. "The World Factbook: Ethiopia." Retrieved February II, 2013 (https://www.cia.gov/library/publications/theworld-factbook/geos/et.html).

Central Statistical Agency [Ethiopia] and ICF International. 2012. Ethiopia Demographic and Health Survey 201I. Addis Ababa, Ethiopia and Calverton, Maryland, USA: Central Statistical Agency and ICF International.

Choi, Jin Young, and Sang-Hyop Lee. 2006. "Does prenatal care increase access to child immunization? Gender bias among children in India." Social Science \& Medicine 63(I): 107- 17.

Dancer, D., and A. Rammohan. 2009. "Maternal autonomy and child nutrition: Evidence from rural Nepal." Indian Growth and Development Review 2(I): 18-38.

Doan, Rebecca Miles, and Leila Bisharat. 1990. "Female autonomy and child nutritional status: The extended-family residential unit in Amman, Jordan." Social Science \& Medicine 3 I (7):783-89.

Entwisle, B. 2007. "Putting people into place." Demography 44(4):687-703.

Fotso, Jean-Christophe, and Barthelemy KuateDefo. 2006. "Household and community socioeconomic influences on early childhood malnutrition in africa." Journal of Biosocial Science 38(03):289-3। 3.

Ghuman, S. J. 2003. "Women's autonomy and child survival: A comparison of Muslims and nonMuslims in four Asian countries." Demography 40(3):419-36.

Gómez, Anu Manchikanti, and Ilene S Speizer. 2010. "Research Community-level intimate partner violence and the circumstances of first sex among young women from five African countries." Reproductive Health 7(I I):8.

Hindin, M.J. 2005. "Women's autonomy, status, and nutrition in Zimbabwe, Zambia, and Malawi." A focus on gender: Collected papers on gender using DHS data:93-II 5.

—. 2006. "Women's input into household decisions and their nutritional status in three resourceconstrained settings." Public Health Nutrition 9(4):485-93. 
Hogan, D.P., B. Berhanu, and A. Hailemariam. 1999. "Household organization, women's autonomy, and contraceptive behavior in southern Ethiopia." Studies in Family Planning 30(4):302-14.

Jejeebhoy, Shireen J. 1995. "Women's education, autonomy, and reproductive behaviour: Experience from developing countries." OUP Catalogue.

Koenig, Michael A, Saifuddin Ahmed, Mian Bazle Hossain, and ABM Khorshed Alam Mozumder. 2003. "Women's status and domestic violence in rural Bangladesh: individual-and community-level effects." Demography 40(2):269-88.

Kravdal, Õstein. 2004. "Child Mortality in India: The Community-Level Effect of Education." Population Studies 58(2): I77-92.

Linnemayr, Sebastian, Harold Alderman, and Abdoulaye Ka. 2008. "Determinants of malnutrition in Senegal: Individual, household, community variables, and their interaction." Economics \& Human Biology 6(2):252-63.

Masudi, UJ. 200I. "Covariates of child mortality in Mali: Does the Health-Seeking Behavior of the mother matter?" Journal of Biosocial Science 33:33 $-54$.

Mistry, Ritesh, Osman Galal, and Michael Lu. 2009. "Women's autonomy and pregnancy care in rural India: A contextual analysis." Social Science \& Medicine 69(6):926-33.

Moursund, Anne, and Õystein Kravdal. 2003. "Individual and Community Effects of Women's Education and Autonomy on Contraceptive Use in India." Population Studies 57(3):285-30I.

Ngom, Pierre, Cornelius Debpuur, Patricia Akweongo, Philip Adongo, and Fred N. Binka. 2003. "Gate-Keeping and Women's Health Seeking Behaviour in Navrongo, Northern Ghana." African Journal of Reproductive Health / La Revue Africaine de la Santé Reproductive 7(I):1726.

Peugh, James L. 20I0. "A practical guide to multilevel modeling." Journal of School Psychology 48(I):85-II 2.

Pongou, Roland, Majid Ezzati, and Joshua Salomon. 2006. "Household and community socioeconomic and environmental determinants of child nutritional status in Cameroon." BMC Public Health 6(I):98.

Prakash, Ravi, Abhishek Singh, Praveen Kumar Pathak, and Sulabha Parasuraman. 20II. "Early marriage, poor reproductive health status of mother and child well-being in India." Journal of
Family Planning and Reproductive Health Care 37(3): I 36-45.

Raudenbush, S.W., and A.S. Bryk. 2002. Hierarchical linear models: Applications and data analysis methods. Newbury Park, CA: Sage.

Raudenbush, S.W., A.S. Bryk, Y.F. Cheong, R. Congdon, and M. Toit. 2004. HLM 6: Hierarchical linear and nonlinear modeling. Lincolnwood: Scientific Software International.

Singh, Kavita, Erica Haney, and Comfort Olorunsaiye. 2012. "Maternal Autonomy and Attitudes Towards Gender Norms: Associations with Childhood Immunization in Nigeria." Maternal and Child Health Journal: I-5.

United Nations [UN].2013. "Millennium Development Goals and Beyond 2015 Fact Sheet". Retrieved September 21, 2013 (http://www.un.org/millenniumgoals/childhealth.s html).

UNDG. 2012. Thematic Paper on MDG 3: Promote Gender Equality and Empower Women. New York: United Nations. Retrieved August 12, 2012 (http://www.unicef.org/mdg/index_genderequalit y.htm).

UNDP. 2012. "Analyzing regional performance and disparities in health outcomes in Ethiopia." edited by United Nations. Addis Ababa.

United Nations Statistics Division. Department of Economic and Social Affairs. 2013. The Millenium Development Goals Report, 2013. New York: United Nations. Retrieved October 2, 2013 (http://mdgs.un.org/unsd/mdg/Host.aspx?Content =Products $/$ ProgressReports.htm).

WHO. 2012. "Immunization, Vaccines, and Biologicals: World Immunization Week 2012." Switzerland: World Health Organization.

Woldemicael, G. 2010. "Do Women With Higher Autonomy Seek More Maternal Health Care? Evidence From Eritrea and Ethiopia." Health Care for Women International 3I (7):599-620.

Woldemicael, G., and E.Y. Tenkorang. 2010. "Women's Autonomy and Maternal HealthSeeking Behavior in Ethiopia." Maternal and Child Health Journal 14(6):988-98. 